\title{
Quality of Life in Children with Narcolepsy
}

\author{
Clara O. Inocente, ${ }^{1}$ Marie-Paule Gustin, ${ }^{2,3}$ Sophie Lavault,, ${ }^{4,5,6}$ Anne Guignard-Perret, ${ }^{1,4,7}$ Aude Raoux, ${ }^{1,4,7}$ \\ Noemie Christol, ${ }^{1,4,7}$ Daniel Gerard, ${ }^{8}$ Yves Dauvilliers, ${ }^{4,9}$ Rubens Reimão, ${ }^{10}$ Flora Bat-Pitault, ${ }^{11}$ Jian-Sheng \\ Lin, ${ }^{1}$ Isabelle Arnulf, ${ }^{4,5,6}$ Michel Lecendreux ${ }^{4,12}$ \& Patricia Franco ${ }^{1,4,7}$
}

1 Integrative Physiology of Brain Arousal System, CRNL, INSERM-U1028, CNRS UMR5292, University Lyon1, Lyon, France

2 Department of Public Health, Université Lyon 1, Institute of Pharmacy (ISPB), Université de Lyon, EA4173, Lyon, France

3 Service de Biostatistique, Hospices Civils de Lyon, Lyon Cedex, France

4 National Reference Centre for Orphan Diseases, Narcolepsy, Idiopathic hypersomnia and Kleine-Levin Syndrome (CNR Narcolepsie-Hypersomnie), Paris, France

5 AP-HP, Groupe Hospitalier Pitié-Salpêtrière, Unité des Pathologies du Sommeil \& Université Pierre et Marie Curie, Paris 6, France

6 Centre de Recherche de I'Institut du Cerveau et de la Moelle épinière, UMR-S975, CNRS UMR7225 \& Inserm U975, Paris, France

7 Pediatric Sleep Unit, Service Epilepsie Sommeil, Explorations Fonctionnelles Neurologiques Pédiatriques, Hôpital Femme Mère Enfant, University

Lyon1, Lyon, France

8 Service de Psychiatrie Infantile, U502, Hôpital Neurologique, University Lyon1, Lyon, France

9 Department of Neurology, Gui-de-Chauliac Hospital, Sleep Disorders Center, Inserm U1061, CHU Montpellier, Montpellier, France

10 Sleep Medicine Advanced Research Group, Division of Clinical Neurology, Clinical Hospital, University of São Paulo School of Medicine, São Paulo, SP, Brazil

11 Child and Adolescent Psychopathology Unit, Salvator Hospital, Public Assistance-Marseille Hospitals, University Aix-Marseille II, Marseille, France

12 Centre pédiatrique des pathologies du sommeil, Hôpital Robert Debré, Paris, France

\section{Keywords}

Child; Depression; Narcolepsy; Quality of life; Sleep.

\section{Correspondence}

Patricia Franco, M.D., Ph.D., Pediatric Sleep Unit, Service Epilepsie, Sommeil, Explorations Fonctionnelles Neurologiques Pédiatriques, Hôpital Femme Mère Enfant, 59 boulevard Pinel, 69500 Lyon, France.

Tel.: +33-427-856-052;

Fax: +33-427-869-230;

E-mail: Patricia.Franco@chu-lyon.fr

Received 10 December 2013; revision 26 April

2014; accepted 30 April 2014

doi: $10.1111 /$ cns. 12291

\section{SUMMARY}

Aims: To evaluate the health-related quality of life (HRQL) and its correlates in children and adolescents with narcolepsy. Methods: We compared the clinical characteristics of control subjects and patients with primary narcolepsy from data collected at the National Reference Centers for Narcolepsy. Results: The cohort included 69 control subjects (29 boys) and 117 patients (65 boys; 59 de novo patients). Cataplexy was present in $81 \%$ and DQB 1*0602 was positive in $91 \%$. The control children were older (13.5 \pm 3.2 vs. $11.6 \pm 3.1$ years, $P<0.001)$ and less obese $(1.4 \%$ vs. $60 \%, P<0.001)$. Twenty-five percent of the patients and $15.6 \%$ of the control subjects had clinically significant depressive feelings on Children's Depression Inventory (CDI $\geq 16$ ) (NS). Fifty-three narcoleptic and 43 control adolescents, 31 narcoleptic children and 23 control children filled out the HRQL questionnaires as well as 83 parents of patients and 60 parents of control subjects. Narcolepsy seriously impacts HRQL in terms of vitality, physical well-being, relations with friends and leisure activities, especially in adolescents. Depression was the factor that most affected HRQL in both narcoleptic and control subjects. For the control subjects and the narcoleptic patients, when the CDI score was entered into the multivariable regression model adjusted for gender and age, no other continuous independent variable could significantly increase the likelihood of the model. When the CDI score increased by 1, the mean HRQL score decreased by 1.7 for narcoleptic patients and 1.5 for control subjects. Apnea-hypopnoea index, diagnosis delay, disease duration, obesity, the presence of cataplexy or treatment had no effects on HRQL. Conclusions: Narcoleptic children and adolescents were at high risk for poor HRQL. Depressive symptoms had a major impact on HRQL. We recommend a more thorough assessment and management of psychological health in this population.

\section{Introduction}

Classical endpoints such as mortality and symptoms are no longer viewed as the only endpoints when considering the efficacy of medical intervention $[1,2]$. Health-related quality of life (HRQL) measurement has become an essential outcome both in population health assessment and in clinical improvement [3]. Current ability to treat children or adolescents with chronic disease, coupled with the inability to offer absolute cure, raises the issue of the quality of life of these children and adolescents. HRQL measurement may be useful to understand the child's or adolescent's perspective in any assessment of treatment outcome in either routine audit work or clinical trials [1]. Narcolepsy with cataplexy is a rare and disabling sleep disorder characterized by excessive daytime 
sleepiness (EDS) and abnormal rapid eye movement (REM) sleep phenomena, including cataplexy (sudden loss of muscle tone triggered by strong emotions), sleep paralysis, hypnagogic hallucinations and sleep-onset REM periods (SOREMPs) [4,5]. Approximately, half of such patients have symptoms of onset prior to the age of 18 years [6-8]. Symptoms are often more severe in children than in adults [8]. Narcolepsy is classified as narcolepsy with (NC) and without cataplexy (NwC) [5]. NC is caused by a deficiency of hypocretin-1 (also called as orexin) peptides released from the dorso-lateral hypothalamic neurons $[9,10]$ probably through autoimmune destruction of hypocretin cells $[11,12]$. As EDS is the major symptom, it undoubtedly has a severe impact on HRQL [13]. In children, EDS is sometimes associated with symptoms of motor hyperactivity. The presence of cataplexy could also aggravate psychosocial consequences. However, the respective burden of cataplexy and EDS is not clearly known. Indeed, children with narcolepsy as well as those with EDS alone have shown significantly lower HRQL, higher rates of depression, and behavioral and educational problems compared with controls [14].

Several factors could influence the HRQL of these children, including age at onset [8], diagnosis delay, disease duration, EDS severity, depressive feelings, hyperactivity symptoms, cataplexy [15], dyssomnia, obesity, and concomitant sleep apnea as well as the presence of treatment. The aim of this study was to evaluate the respective impact of these factors on HRQL in a series of children and teenagers with narcolepsy and to compare it with that of control children and adolescents followed in the national reference centers.

\section{Methods}

\section{Patients and Control Subjects}

This study was based on the data collected on a large cohort of narcoleptic children and control subjects (NARCOBANK). All of these patients were diagnosed with primary narcolepsy after a complete evaluation [5]. The children were followed up in the Robert Debré Children's Hospital in Paris (patients $n=65$, controls $\mathrm{n}=19$ ), the Mother-Children's Hospital in Lyon (patients $\mathrm{n}=39$, controls $\mathrm{n}=14$ ), the Gui-de-Chauliac Adult's Hospital in Montpellier (patients $n=8$ ) and the Pitié-Salpêtrière Adult's Hospital in Paris (patients $n=5$, controls $n=36$ ). A description of the patient cohort has already been reported [16]. The patient cohort included 117 children (65 boys; 59 de novo patients) with a mean age of $11.6 \pm 3.1$ years and a median age of 12 years (from 5 to 17 years) on diagnosis. Cataplexy was present in $81 \%$, and DQB $1 * 0602$ was positive in $91 \%$. Control subjects were also included in this study. The control children ( $\mathrm{n}=69,29$ boys) had a mean age of $13.5 \pm 3.2$ years and a median age of 14 years (from 7 to 17 years). Most of the control children and adolescents were recruited from the children of the nurses and medical staff or their best friends in the authors' departments. This study was approved by the local ethics committees (PHRC AOM07-138). All of the parents signed the written form, and the children gave their informed consent to take part in this research program on their disease which included a long and systematic interview of the patient (and parents) with the neurologist or the pediatrician in charge.

\section{Investigations}

The patients had an initial consultation and follow-up visits with the certified sleep specialists (ML, PF, AGP, AR, YD, IA) who were also in charge of treating them. All measurements were collected and analyzed by the research assistants (CI, SL).

\section{Questionnaires}

Patients and control subjects completed a standardized sleep questionnaire. Daytime sleepiness was evaluated in 73 patients and 37 controls with the Adapted Epworth Sleepiness Score (AESS), in which the item "falling asleep while in a car stopped in the traffic" was replaced with "falling asleep at school" [17] and in 72 patients and 58 controls with the Pediatric Daytime Sleepiness Scale (PDSS) [18], while 44 patients and 35 controls completed both sleepiness questionnaires. The pathological scores were $>10$ and $>16$ in these two questionnaires, respectively.

The severity of cataplexy was evaluated in 87 patients by the Cataplexy Severity Rating Score $1=$ moderate weakness, for example, head drop or jaw opening; 2 = can maintain posture with external support; $3=$ loses posture and falls to the ground [19]. The frequency of cataplexy attacks was also evaluated from 0 : less than one episode per year; 1 : more than one attack per year; 2 : more than one attack per month, 3 : more than one episode per week; 4 : more than one episode per day [6]. No cataplexy was reported by the control subjects.

The Children's Depression Inventory (CDI) was used to assess for symptoms of Major Depressive Disorder (MDD) in 88 patients and 64 controls [20]. This questionnaire includes 27 items scoring from 0 to 2. Depression was categorized by the presence and severity of symptoms with a CDI score greater or equal to 16 . Although this scale has been widely used in research on sleep and depression [21], it should be noted that the CDI score reflects depressive symptoms rather than providing for each age and sex a clear clinical diagnosis of MDD according to DSM-IV. Ninety-three patients and 66 control subjects filled out the Insomnia Severity Index (ISI) which contains seven questions scored from 0 to 4 , with a maximum of 28 and an abnormal score when $>10$ [22]. Symptoms associated with hyperactivity and attention deficit [23] were scored by 85 parents of patients and by 61 parents of control subjects using the Conners Parents Rating Scale-Revised (CPRSR) (48 items) with six subscores: conduct, learning, psychosomatic symptoms, impulsivity, anxiety, and hyperactivity. Moderate to severe symptoms were defined with a cutoff above 65, severe symptoms with a cutoff above 75 . Fatigue was scored with the Chalder's fatigue scale [24] in 89 patients and 65 control subjects scored from 0 to 14, with abnormal cutoff score above 10. Parents also answered questions about their childrens' school difficulties, grade repetition, or absenteeism. A status of yes/no was used to categorize these responses.

Health-related quality of life was assessed using a questionnaire adapted for adolescents (VSP-A) [25], for children and parents [26]. VSP-A [2,25], Vécu et Santé Perçue de l'Adolescent, is a self-questionnaire for adolescents from 11 to 18 years, with the following dimensions: psychological and physical well-being, body image, vitality, friends, parents, teachers, medical staff, leisure, school performance, and a global HRQL index (range: 
0-100). Lower scores correspond to a poorer quality of life. As the adolescents often did not answer the questions related to their sentimental life, the total score could or not include this dimension. VSP-P can also be filled by the parents to have the perception of the HRQL of their children [27]. The VSP-A was adapted for children (8-10 years) (VSP-E) [28], Vécu et Santé Perçue par l'Enfant with nine items: general well-being, energy/ vitality, self/body image, relations with friends, parents, medical staff, leisure, school and global HRQL index corresponding to the HRQL index of adolescents minus sentimental life and relations with teachers. These questionnaires were validated in 1057 adolescents with no acute or chronic diseases (mean age 14.8 years, sex ratio 0.9) [2] and 663 healthy children (mean age 10.3 years, sex ratio 0.9) in the French population [26]. In our study, 53 narcoleptic and 43 control adolescents, 31 narcoleptic children, and 23 control children filled out these questionnaires as well as 83 parents of patients and 60 parents of control subjects. To compare patients with control subjects, the item interaction with medical staff item was not included in the total HRQL score.

\section{Diagnostic Procedure for Narcolepsy}

The sleep- and wake-monitoring procedure included (1) a complete clinical examination; (2) a sleep log of 15 days preceding the sleep laboratory evaluation; (3) a polysomnography with respiratory monitoring from $8 \mathrm{pm}$ to $7 \mathrm{am}(\mathrm{n}=109)$; (4) followed by $4(\mathrm{n}=48)$ or $5(\mathrm{n}=55)$ standard multiple sleep latency tests (MSLT) at $9 \mathrm{am}, 11 \mathrm{am}, 1 \mathrm{pm}, 3 \mathrm{pm}$ and $5 \mathrm{pm}$, that were terminated after $20 \mathrm{~min}$ if no sleep occurred, and after 15 min asleep if sleep occurred [29]. Polysomnographic recordings (PSG) included an electroencephalography (Fpl-A2, C3-A2, O1-A2), left and right electro-oculograms, levator menti surface electromyography, nasal pressure trough cannulae, respiratory efforts using thoracic and abdominal belts, position, ECG, transcutaneous oximetry and end tidal $\mathrm{CO}_{2}$ values $(\mathrm{n}=26)$ during the night. Sleep stages, arousals, and respiratory events were scored visually according to standard pediatric criteria [29]. The total sleep time (TST), total sleep period, sleep and REM sleep latencies, the durations and percentages of non-REM sleep (NREM) stage (N1, N2, N3), and REM sleep (R) were determined during night recording as well as the indexes of sleep fragmentation (i.e., the arousal index, respiratory arousal index [RAI]), apnea-hypopnea index, minimal and mean oxygen saturation during sleep, maximum end tidal $\mathrm{CO}_{2}$ values in NREM and REM sleep and percent of $\mathrm{CO}_{2}$ values $>50 \mathrm{mmHg}$ during TST. Obstructive hypoventilation was defined by more than $25 \%$ of TST with $\mathrm{CO}_{2}$ higher than $50 \mathrm{mmHg}$ [29]. Respiratory sensors were removed during MSLT. Mean sleep latency and number of sleeponset REM periods were calculated on MSLT [29].

\section{Criteria for Idiopathic Narcolepsy}

All of the patients met the criteria for idiopathic narcolepsy [5] including: (1) complaints of EDS for at least 3 months; (2) symptoms not better explained by other medical or psychiatric disorders; (3) the absence of secondary narcolepsy; (4) the presence of clear-cut cataplexy and/or (5) mean sleep latency during MSLT $<8$ min plus two or more sleep-onset REM periods. HLA-DR-DQB1*0602 genotyping was performed in most patients $(\mathrm{n}=104)$. Brain magnetic resonance imaging was also often performed to rule out symptomatic narcolepsy $(n=70)$ [30].

Hypocretin-1 (orexin-A) was also determined in 20 patients with narcolepsy in duplicate from cerebrospinal fluid (CSF) samples without prior extraction using 125I radioimmunoassay kits from Phoenix Peptide, Inc, according to manufacturer guidelines. The detection limit was $10 \mathrm{pg} / \mathrm{mL}$ and intra-assay variability was $<10 \%$. CSF hypocretin-1 levels below $110 \mathrm{pg} / \mathrm{mL}$ were considered as low, intermediate between 110 and 200, and normal over 200. All values were back-referenced to Stanford reference samples (HHMI Stanford University Center for Narcolepsy, Palo Alto, CA, USA).

\section{Anthropometric Measurements}

Height and weight were obtained in each child and body mass index $\left(\mathrm{BMI}=\right.$ weight $/$ height $\left.^{2}\right)$ was calculated. BMI $z$-score representing a measure of weight, adjusted for height, sex, and age, relative to a smoothed reference distribution [31], was computed. In medical practice, BMI growth curves are usually used. Obesity was defined by BMI greater than the 97th percentile for age and sex [32,33]. Age at menarche was known in 31 girls. We did not have information about the secondary sexual characteristics at the onset of symptoms to establish the presence of precocious puberty [34]. Defined using the 5th percentile of the distribution in the French Health Behavior in school-age children, early menarche was defined as menarche from 9 to 11 years [35]. Tanner staging was performed on inclusion in the study [36].

\section{Statistical Analysis}

Quantitative variables were expressed as mean and standard deviation. HRQL of the narcoleptic patients was compared with those of control subjects using Wilcoxon tests for quantitative variable because of the non-normality of the data assessed by Shapiro-Wilk test. Fisher's exact test was used for betweengroup comparisons of dichotomous variables and $\chi^{2}$ test for polychromous variables. No imputation of missing data was performed. Bivariate associations were performed to analyze the association between HRQL and the other variables. Owing to missing data, we had a different number of subjects for each couple of variables. We therefore computed the linear coefficient of correlation and the adjusted coefficient of determination just after standardization of the two variables for each couple. To standardize a variable, we took the normal percentile of the rank of each value for a given couple. The coefficient of determination can then be interpreted as the percentage of variability of one variable "explained" by the other expressed in standard units. Package corrplot function was used to represent the coefficient of correlation. Multivariate linear models were adjusted for gender and age ( $\leq 10$ years vs. $>10$ years) according to the categorized depression score. Each continuous significant independent variable was then entered into the multivariate linear model. The significance level was set at 5\%. Statistical 
calculations were performed using $\mathrm{R}$ language, version 2.15.2 (http://cran.r-project.org/).

\section{Results}

\section{Clinical, Polygraphical, and Biological Characteristics of the Population}

The control children ( $\mathrm{n}=69,29$ boys) were older $(P<0.001)$, less obese $(1.4 \%)(P<0.001)$, and ate less during the night $(P=0.02)$ (Table 1). From the 41 children diagnosed after 2009, 13 narcoleptic patients $(31.7 \%)$ had received $\mathrm{HINl}$ vaccination prior the onset of symptoms. Six of the 62 control subjects have received HlNl vaccination $(9.6 \%)(P=0.01)$. Thirteen patients $(11 \%)$ had an autoimmune disease, including diabetes type $1(\mathrm{n}=3)$, psoriasis $(n=2)$, Crohn's disease $(n=1)$, lupus $(n=1)$, retinitis pigmentosa $(n=1)$, central hypothyroidism $(n=2)$, HIV infection $(\mathrm{n}=1)$, and rheumatoid arthritis $(\mathrm{n}=2)$. No control subjects had autoimmune diseases $(P=0.010)$.

Compared with the control subjects, patients had more hypnagogic hallucinations, sleep paralysis, somniloquia, personal and familial parasomnia. No control children had cataplexia.

\section{Sleepiness, Mood, Fatigue, Hyperactivity, and School Problems}

The sleepiness, fatigue, insomnia, mood, hyperactivity scores, and school problems are shown in Table 2. The narcoleptic patients had higher scores on AESS, PDSS, ISI, fatigue, CDI, CPRS-R questionnaires than the control subjects. Twenty-five percent of the patients and $15.6 \%$ of the control subjects had clinically significant depressive feelings (CDI $\geq 16$ ) (NS), $7 \%$ had a high level of Attention Deficit/Hyperactivity Disorder symptoms (CPRS$\mathrm{R}>75$ ) versus $1.6 \%$ in the control group (NS). Forty-one percent of the patients versus $7.5 \%$ of the controls reported school difficulties $(P=0.002)$, while $28 \%$ of the patients versus $7.5 \%$ of the controls did not pass a grade and repeated it prior to narcolepsy diagnosis $(P<0.001), 30 \%$ of the patients versus $8.9 \%$ of the controls had absenteeism $(P=0.002)$.

\section{Quality of Life}

Fifty-three narcoleptic and 43 control adolescents, 31 narcoleptic children and 23 control children filled out the HRQL questionnaires as well as 83 parents of patients and 60 parents of control

Table 1 Demographic and anthropometric characteristics of narcoleptic patients and control subjects

\begin{tabular}{|c|c|c|c|}
\hline & Narcoleptic patients & Control subjects & $P$ \\
\hline $\mathrm{n}(\%)$ & 117 & 69 & \\
\hline Male, n (\%) & $65(55.5)$ & $29(42)$ & 0.10 \\
\hline African origins, $\mathrm{n}(\%)$ & 37 (31.6) & $19(29.2)$ & 0.77 \\
\hline Age at study inclusion, year & $12(5-17.5)$ & $14(7-17.8)$ & $<0.001$ \\
\hline Allergy, n (\%) & $33(29.7)$ & $20(32.8)$ & 0.80 \\
\hline Autoimmune disease, n (\%) & $13(11.1)$ & $0(0)$ & 0.01 \\
\hline $\begin{array}{l}\text { H1N1 vaccination prior onset, } \\
n>2009(\%)\end{array}$ & $13 / 41(31.7)$ & $6 / 62(9.6)$ & 0.01 \\
\hline Body mass index-Z score & $2.36(-2.34$ to 10.82$)$ & $0.85(-1.64$ to 6.49$)$ & $<0.001$ \\
\hline Obesity, n (\%) & $70(59.8)$ & $1(1.4)$ & $<0.001$ \\
\hline Night eating, $\mathrm{n}(\%)$ & $15(17.4)$ & $2(3.4)$ & 0.02 \\
\hline Age at menarche, year & $11(9-17)$ & $12(10-15)$ & 0.15 \\
\hline Early menarche $<10$ years & $8 / 31(25.8)$ & $3 / 26(11.5)$ & 0.30 \\
\hline Cataplexy, n (\%) & $95(81.2)$ & $0(0)$ & $<0.001$ \\
\hline Hypnagogic hallucinations, n (\%) & $47(40.2)$ & $2(2.9)$ & $<0.001$ \\
\hline Sleep paralysis, n (\%) & $29(24.8)$ & $2(2.9)$ & $<0.001$ \\
\hline Dyssomnia, n (\%) & $19(16.2)$ & $8(13.6)$ & 0.44 \\
\hline Somniloquia, n (\%) & $85(72.6)$ & $29(45.3)$ & $<0.001$ \\
\hline Somnanbulism, n (\%) & $24(20.5)$ & $8(12.9)$ & 0.173 \\
\hline Parasomnia, n (\%) & $87(74.4)$ & $27(45)$ & $<0.001$ \\
\hline Familial parasomnia, n (\%) & $35(29.9)$ & $8(13.6)$ & $<0.001$ \\
\hline HLA DQB1*0602, n\% & 95/104 (91.3) & & \\
\hline \multicolumn{4}{|l|}{ Polysomnography ( $n=109$ ) } \\
\hline Total sleep time, min & $479(270-795)$ & & \\
\hline Sleep efficiency,\% & $84(29-98)$ & & \\
\hline Sleep onset, $\min$ & $9(0-187)$ & & \\
\hline $\begin{array}{l}\text { Rapid eye movement (REM) } \\
\text { sleep onset, min }\end{array}$ & $73(0-385)$ & & \\
\hline \multicolumn{4}{|l|}{ Multiple sleep latency tests $(n=103)$} \\
\hline Mean sleep latency, min & $4(0.5-15)$ & & \\
\hline Sleep onset in REM periods, $n$ & $4(0-5)$ & & \\
\hline
\end{tabular}

Data are given for 117 patients and 69 control subjects, except when $\mathrm{n}$ is specified. To compare patients and control children, significant levels were given $(P)$. Data were expressed in mean \pm SD. 
Table 2 Sleepiness, fatigue, mood, hyperactivity, quality of life, and school problems in narcoleptic patients and control subjects

\begin{tabular}{|c|c|c|c|}
\hline & $\begin{array}{l}\text { Narcoleptic } \\
\text { patients }\end{array}$ & $\begin{array}{l}\text { Control } \\
\text { subjects }\end{array}$ & $P$ \\
\hline $\begin{array}{l}\text { Adapted Epworth } \\
\text { sleepiness score } \\
(0-24)\end{array}$ & $16(4-23)$ & $6(0-13)$ & $<0.001$ \\
\hline Score $>10, n(\%)$ & $69 / 73(94.5)$ & 5/37 (13.5) & $<0.001$ \\
\hline $\begin{array}{l}\text { Pediatric Daytime } \\
\text { Sleepiness Scale } \\
(0-32)\end{array}$ & $16(0-27)$ & $10.5(1-23)$ & $<0.001$ \\
\hline Score $>16, n(\%)$ & $38 / 72(52.7)$ & $8 / 58(13.8)$ & $<0.001$ \\
\hline Fatigue scale & $8(1-14)$ & $2(0-12)$ & $<0.001$ \\
\hline Score $>10, n(\%)$ & $24 / 89(26.9)$ & $1 / 65(1.5)$ & $<0.001$ \\
\hline $\begin{array}{l}\text { Insomnia Severity } \\
\text { Index (0-28) }\end{array}$ & $12(1-22)$ & $5(0-17)$ & $<0.001$ \\
\hline Score >10, n (\%) & $59 / 98(60.2)$ & $9 / 66(13.6)$ & $<0.001$ \\
\hline $\mathrm{CDI}$ & $12(1-33)$ & $7(1-27)$ & $<0.001$ \\
\hline Score $\geq 16, n(\%)$ & $22 / 88(25)$ & 10/64 (15.6) & 0.23 \\
\hline $\begin{array}{l}\text { Conners Parent } \\
\text { Rating scale }\end{array}$ & $52(35-120)$ & $42(35-82)$ & $<0.001$ \\
\hline $\begin{array}{l}\text { Hyperactivity } \\
\text { score } \\
>65, n(\%)\end{array}$ & 20/85 (23.5) & $6 / 61(9.8)$ & 0.056 \\
\hline $\begin{array}{l}\text { Hyperactivity } \\
\text { score } \\
>75, \mathrm{n}(\%)\end{array}$ & $6 / 85(7)$ & $1 / 61(1.6)$ & 0.26 \\
\hline $\begin{array}{l}\text { Quality of life } \\
\text { (Parents) }\end{array}$ & $\begin{array}{l}61.7(28.5-91) \\
\mathrm{n}=83\end{array}$ & $\begin{array}{l}73.7(51.2-98.8) \\
n=60\end{array}$ & $<0.001$ \\
\hline $\begin{array}{l}\text { Quality of life } \\
\text { (Adolescents) }\end{array}$ & $\begin{array}{l}60.4(25.7-90.7) \\
n=52\end{array}$ & $\begin{array}{l}69.5(16.6-93) \\
n=43\end{array}$ & 0.008 \\
\hline $\begin{array}{l}\text { Quality of life } \\
\text { (Children) }\end{array}$ & $\begin{array}{c}58.8(35.6-90.2) \\
\mathrm{n}=31\end{array}$ & $\begin{array}{l}75.8 \text { (44.9-97), } \\
\mathrm{n}=23\end{array}$ & 0.001 \\
\hline Grade repetition & 30/105 (28.6) & $5 / 66(7.6)$ & 0.002 \\
\hline School difficulties & 43/105 (40.9) & $5 / 66(7.5)$ & $<0.001$ \\
\hline Absenteeism & $31 / 102(30.4)$ & $6 / 66(8.9)$ & 0.002 \\
\hline
\end{tabular}

CDI, Children's Depression Inventory. To compare patients and control children, significant levels were given $(P)$. Data were expressed in mean $\pm S D$.

subjects (clinical characteristics in Tables S1 and S2). On the other hand, no difference was found between patients and control subjects who filled and those who did not fill the HRQL questionnaire.

\section{Narcoleptic Patients versus Control Subjects}

Compared with the control children $(n=23$, nine boys, $9.7 \pm 4.6$ years), the narcoleptic children ( $\mathrm{n}=31,18$ boys, $8.6 \pm 1.7$ years) had lower HRQL $(P=0.001)$ with lower vitality $(P=0.003)$, general well-being $(P=0.002)$, poorer self-image $(P=0.03)$ and tended to have less contact with their parents $(P=0.06)$ and lower school performances $(P=0.06)$ (Figure $1 \mathrm{~A})$. The narcoleptic adolescents $(\mathrm{n}=53,25$ boys, $13.8 \pm 2.1$ years $)$ had a lower quality of life index $(P=0.008)$, lower physical wellbeing $(P<0.001)$, fewer friends $(P=0.001)$, and leisure activities $(P=0.006)$ than the control adolescents $(\mathrm{n}=43,18$ boys, $15.5 \pm 1.5$ years) (Figure 1B).
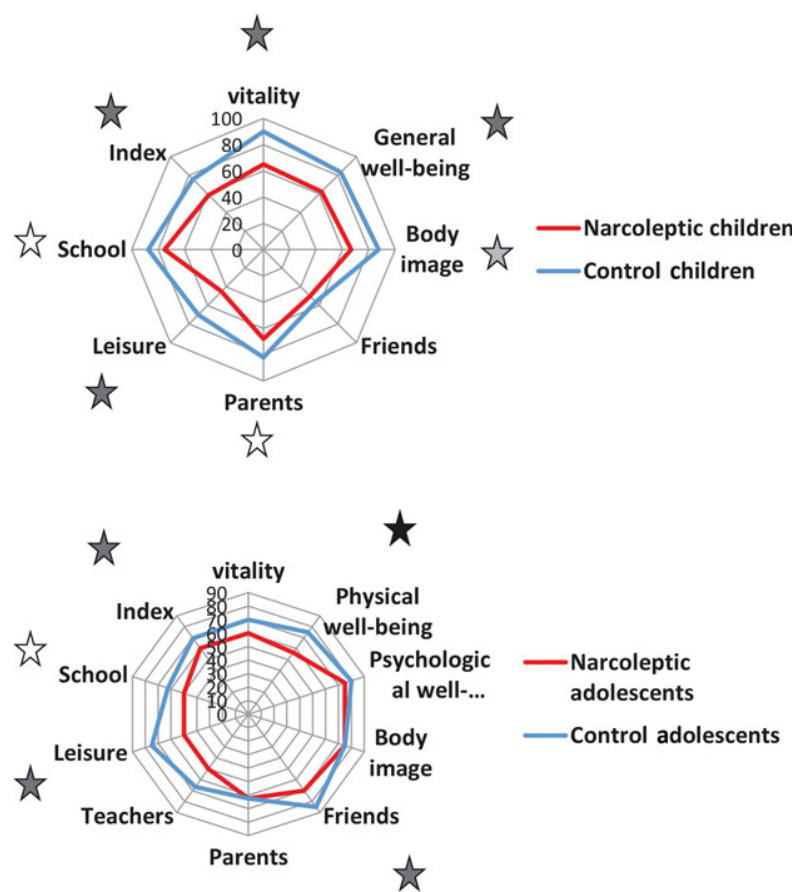

Figure 1 Quality of life between control and narcoleptic patients. $P<0.001$ (black star), $P<0.01$ (dark gray star), $P<0.05$ (light gray star), $P<0.1$ (ઐ)

\section{Children versus Adolescents}

The narcoleptic adolescents had more contact with their friends $(P=0.003)$, had more leisure activities $(P=0.005)$ and lower performances in school $(P=0.034)$ than the narcoleptic children (Figure 2A). In the control group, these differences already existed between the adolescents and the children. Indeed, the adolescents had more interactions with their friends $(P<0.001)$, less contact with their parents $(P=0.036)$, lower school performance $(P=0.004)$ and vitality $(P<0.001)$, and tended to have lower general well-being $(P=0.06)$ than the control children (Figure 2B).

\section{Parents versus Children or Adolescents}

The parents of narcoleptic patients had a good perception of the quality of life in their children and adolescents. In the control adolescents, the parents overestimated energy $(P=0.002)$, psychological well-being $(P=0.022)$ and the school performance $(P=0.006)$ of their adolescents. In the control children, the parents underestimated the energy of their children $(P=0.016)$.

\section{Patient Treatment}

Fifty-nine patients were de novo and had never been treated, five patients had stopped their treatment, and 53 had already been treated for a median of 15 months when included in the study. Patients received modafinil $(\mathrm{n}=44)$ and methylphenidate $(\mathrm{n}=16)$ as stimulants, whereas mazindol $(\mathrm{n}=3)$, $\mathrm{D}$-amphetamine $(n=1)$, and adrafinil $(n=1)$ were rarely used. These 



Figure 2 Comparison between children and adolescents. $P<0.001$ (black star), $P<0.01$ (dark gray star), $P<0.05$ (light gray star), $P<0.1$ (放).

treatments were combined in 13 patients. Venlafaxine $(\mathrm{n}=9$, 37.5-75 mg/day) was usually used for cataplexy. However, sodium oxybate $(\mathrm{n}=3)$ and mazindol $(\mathrm{n}=3)$ had positive effects on both EDS and cataplectic attacks. Compared with the new patients, treated patients had lower AESS scores $(P=0.049)$ but not significantly lower PDSS scores (NS).

Concerning HRQL, no differences were found between treated versus nontreated patients. Twenty-seven treated adolescents, 27 treated children, and 50 parents of treated patients filled the HRQL questionnaires. Of these 50 treated patients, 48 received modafinil, 2 methylphenidate, 4 a combination of methylphenidate and modafinil, one mazindol and modafinil.

\section{School Functioning}

Both patients and control subjects with school difficulties had lower total HRQL $(P<0.001)$. We found the same results in the narcoleptic patients $(P=0.039)$ and tended to reach significance in the control group $(P=0.077)$. For the whole group, subjects and patients with school difficulties had lower energy $(P=0.001)$, physical well-being $(P=0.004)$, psychological well-being $(P=$ $0.003)$, self-esteem $(P=0.016)$, relations with friends $(P=0.018)$, leisure activities $(P=0.017)$, school performance $(P=0.002)$ than those without school difficulties. For the patients and control subjects who repeated a year, we found lower energy $(P<0.001)$, physical well-being $(P=0.007)$, total HRQL score $(P=0.049)$ than for those who did not. Patients and control subjects with absenteeism had lower energy $(P=0.006)$, physical well-being
$(P<0.001)$, psychical well-being $(P=0.006)$, school performance $(P=0.03)$, and total HRQL score $(P=0.003)$ than those who had no absenteeism.

\section{Quality of Life and Covariates Bivariate Associations}

For the narcoleptic patients, the bivariate association between the dimensions of HRQL and continuous covariates are provided in Table S3 and Figure 3. Depression was the factor that most affected the quality of life (53\%), followed by behavioral problems $(22 \%)$, fatigue $(14 \%)$, hyperactivity $(12 \%)$, daytime sleepiness $(11 \%)$, anxiety $(11 \%)$, and insomnia $(7 \%)$. In the narcoleptic patients, depressive feelings mostly decreased energy (48\%), general well-being $(46 \%)$, physical $(45 \%)$, and psychological wellbeing $(40 \%)$.

For the control subjects, the bivariate association between the dimensions of HRQL and continuous covariates are provided in Table S4 and Figure 4. Depression was the factor that most affected the quality of life $(49 \%)$, followed by anxiety $(29 \%)$, insomnia $(26 \%)$, behavioral problems $(13 \%)$, and learning $(13 \%)$. In the control subjects, depressive feelings mostly decreased energy (36\%), general well-being (41\%), physical $(40 \%)$, and psychological well-being (57\%).

\section{Multivariable Regression Model}

For the narcoleptic patients, when the CDI score was entered into the linear model adjusted for gender and age, no other continuous independent variable could significantly increase the likelihood of the model. Indeed, depressive feelings were associated with fatigue $\left(R^{2}=48 \%\right)$, hyperactivity $\left(R^{2}=31 \%\right)$, behavioral problems $\left(R^{2}=28 \%\right)$, learning difficulties $\left(R^{2}=27 \%\right)$, and EDS (PDSS)

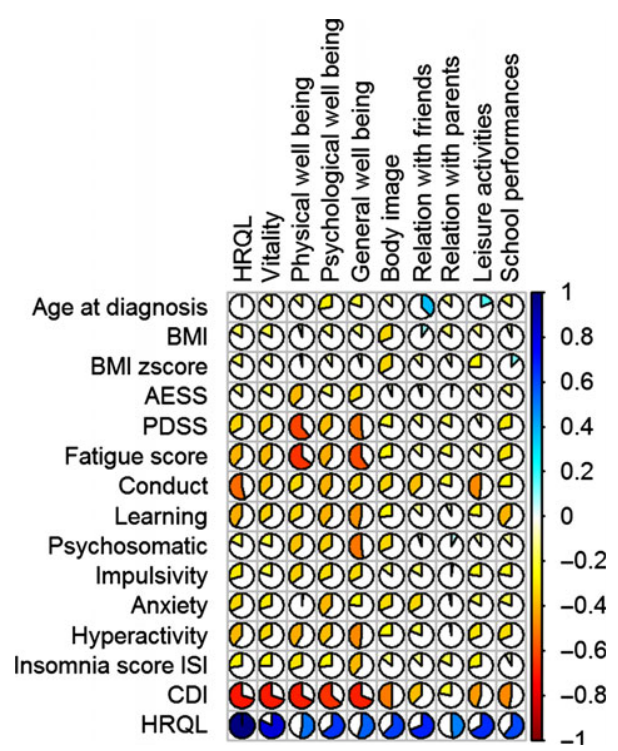

Figure 3 Bivariate associations between health-related quality of life (HRQL) variables and covariates in narcoleptic children. Negative associations in red, positive associations in blue. 




Figure 4 Bivariate associations between health-related quality of life (HRQL) variables and covariates in control subjects. Negative associations in red, positive associations in blue.

$\left(R^{2}=24 \%\right)$. The retained model with gender, age, and CDI score as independent variables "explained" $56 \%$ (adjusted $R^{2}=0.56$ ) of the variability of the HRQL score $(n=80)$. In this model, when the CDI score increases by 1 , the mean HRQL score decreases by 1.7. The same trend was observed with the energy score as a dependent variable with a larger size effect. When the depression score increased by 1 , the mean energy score decreased by 2.5 . The same trend was observed with physical and psychological wellbeing. Obesity, the presence of cataplexy, treatment or comorbidities did not change the associations. For the HRQL score without medical staff interaction, the results were similar $(-1.8, P<$ $0.001)$.

For the control subjects, we found the same results with a mild intensity. There was no significant effect of gender and age but there was a determinant effect of depression. In the model for control subjects, when the CDI score increases by 1 , the mean HRQL score decreases by 1.5. No effect was found for insomnia or anxiety.

When the narcoleptic patients and control subjects were in the same model, we found the effect of depression $(-1.76, P<0.001)$ as well as the effect of narcolepsy $(-5.89, P=0.001)$.

\section{Discussion}

Narcolepsy impacts HRQL in terms of vitality and physical wellbeing. As a multidimensional measure, HRQL attempts to identify the most relevant aspects of health, which in adolescence and childhood are both physical and emotional well-being and selfesteem, and social functioning perception with peers, parents and teachers. This questionnaire has been largely validated in the French pediatric population. The characteristics of this subsample were similar to those of the French population attending school: age, gender, grade, or location in socioeconomic area [25]. The comparison of the VSP-A scores across health data led to expected results. The narcoleptic patients reported lower HRQL than others on vitality and physical well-being, general HRQL index. These results are consistent with those reported in the literature comparing healthy with sick pediatric patients $[2,37,38]$. Narcoleptic patients, especially adolescents reported fewer relations with friends and lower leisure activities than healthy subjects. Even if the social bond with friends persists, lack of vitality causes restrictions of leisure activities. This is particularly true in adolescents. On the other hand, the observed differences were consistent with the expected ones. Compared with narcoleptic children, narcoleptic adolescents had higher scores for the dimensions dealing with relations with friends, leisure and lower scores on school performance.

Only Stores et al. [14] have studied the effect of narcolepsy on HRQL in pediatrics. In the adult population, the health, social, economic consequences of narcolepsy have been evaluated by several authors $[39,40]$. The accumulation of different clinical symptoms as well as the "social dysfunction" associated with the disease could cause deterioration in physical and psychosocial function as well as emotional health and hence considerably affect the quality of life in those patients [13,41-44]. A similar pattern of impairment of health status was found in our study. In particular, the lowest scores were in the domains of energy/vitality, physical and psychological well-being. Energy/vitality was the first affected dimension of HRQL in our study. Patients with narcolepsy experience EDS with unexpected irresistible sleep episodes. These clinical symptoms could lead to a feeling of physical tiredness, causing reduced energy, fatigue and vitality as documented by the patients. Physical health and lack of vitality limits patients by restricting the type and amount of time spent on home life, social activities, and school performances. Hyperactivity, behavioral problems, fatigue, EDS, and insomnia also negatively influenced HRQL. However, depressive feelings represented the major factor influencing HRQL. This strict relationship between mood symptoms and HRQL has already been found in previous observations in adult [13,41-46] and pediatric patients [14]. In adult patients, the frequency of depressive symptoms ranges from 15\% to $56.9 \%$ [13,41-46]. Depression could be intrinsic to the pathophysiology of narcolepsy or secondary to the complications of the disease. Indeed, hypocretins modulate stress reactions through stimulation of the hypothalamus-pituitary-adrenal axis, as well as motivated behavior. As a consequence, hypocretin deficiency in NC could also promote mood disorders. The psychosocial impact of narcolepsy and difficulty to cope with sleepiness could also expose patients to the risk of exogenous depression. Behavioral problems, emotional problems with depression, and social difficulties have been reported in $33 \%, 44 \%$, and $66 \%$ of narcoleptic children in the different series $[15,47,48]$. Another hypothesis was that depressed subjects may have cognitive biases favoring negative self-related information or interpretations of ambiguous situations $[49,50]$. Like others, we found that cataplexy did not show any correlation with HRQL scales [42-44]. This finding is corroborated by the similarity of HRQL profile in IH (by definition without cataplexy) and narcolepsy found by Stores et al. [14]. However, this could be explained by the fact that there were few narcoleptic patients without cataplexy in our series. No effect was found for disease duration for diagnosis delay either. Therapy status (taking drugs for narcolepsy or not) or obesity did not reach any statisti- 
cally significant correlation with HRQL. Therapy has been reported to not influence the depressive feelings in adult narcoleptic patients and thus the quality of life of these patients [13].

The influence of this pathology on HRQL would appear to be less accentuated in pediatric patients than in the adult population. This phenomenon could also be attributable to the fact that in adult populations, work, and marital situation play a more important role than in the case of adolescents who are attending school. Fifty-nine percent of the adult patients were unemployed [44] and $56 \%$ reported difficulties in their private relationships [5153]. Thirteen percent described restrictions in their education because they had been unable to complete the qualification process they had begun.

Our study has several limitations. We report one of the largest series of narcoleptic children that we compared with control subjects. However, these retrospective data came from different reference centers. We used the same procedures except for different daytime sleepiness questionnaires and number of MSLT tests. The cutoff to compare younger to older patients was arbitrarily chosen at 10 years. Indeed, we used the VSA adapted for children, and this questionnaire was validated until 10 years. For adolescents, we used the Vécu et Santé Perçue de l'Adolescent, that is, a selfquestionnaire for adolescents from 11 to 18 years. So the cutoff was imposed by the choice of the questionnaires that were validated for these ranges of ages. On the other hand, for HQRL data, the mean age of narcoleptic children was $8.6 \pm 1.7$ years versus $9.7 \pm 1.6$ years, and the mean age of adolescent was for narcoleptic patients $(13.8 \pm 2.1$ years $)$ and for control adolescents $(15.5 \pm 1.5$ years $)$.

In this study, only some of our children had CSF hypocretin-1 measurements. Data concerning the socio-economic level was not collected. Secondly, this study was not based on an epidemiological survey of patients with narcolepsy but included patients consecutively seen in highly specialized units. As patients were not included in different levels of care, a bias could be possible toward more severely affected patients and hence a bias toward patients with decreased HRQL. Unfortunately, our study design did not allow us to clearly distinguish different severity states of the disease. Finally, most of the control children and adolescents were recruited from the children of nurses and medical staff or their best friends in the authors' departments. However, the results were similar to those previously obtained in larger, nonselected populations $[25,26]$. The control subjects were older and less obese than the patients. In the multivariate model, no effect was found for age, sex, or obesity.

In conclusion, the present findings lend weight to the belief that narcoleptic children and adolescents are at high risk of poor HRQL. Depressive symptoms had a major impact on HRQL. Other factors such as hyperactivity, fatigue, EDS, and insomnia also negatively influenced HRQL.

These findings could indicate how such disadvantages might be prevented or minimized to avoid such serious difficulties in adult life. We recommend a more thorough assessment of the psychological health in this population and more aggressive treatment of depression through psychological management and antidepressive therapy at adapted doses. On the other hand, patients with narcolepsy must be encouraged to participate in leisure activities as long as possible to considerably increase the HRQL and well-being in those patients. For school performance, educational teams and school health personnel must be encouraged to set up more adapted educational or medical strategies. Prospective studies are needed to confirm these results and to find the best strategies to manage mood symptoms and to improve HRQL in narcoleptic children.

\section{Conflict of Interest}

The authors declare no conflict of interest.

\section{References}

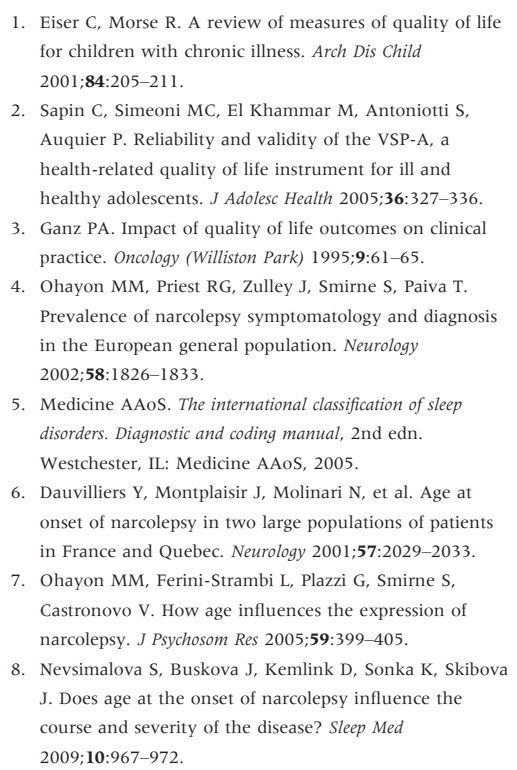

9. Peyron C, Faraco J, Rogers W, et al. A mutation in a case of early onset narcolepsy and a generalized absence of hypocretin peptides in human narcoleptic brains. Nat Med 2000;6:991-997.

10. Thannickal TC, Moore RY, Nienhuis R, et al. Reduced number of hypocretin neurons in human narcolepsy. Neuron 2000;27:469-474.

11. Aran A, Lin L, Nevsimalova S, et al. Elevated anti-streptococcal antibodies in patients with recent narcolepsy onset. Sleep 2009;32:979-983.

12. Cvetkovic-Lopes V, Bayer L, Dorsaz S, et al. Elevated Tribbles homolog 2-specific antibody levels in narcolepsy patients. J Clin Invest 2010;120:713-719.

13. Dauvilliers $Y$, Paquereau J, Bastuji H, Drouot $X$, Weil JS, Viot-Blanc V. Psychological health in central hypersomnias: The French Harmony study. J Neurol Neurosurg Psychiatry 2009;80:636-641

14. Stores G, Montgomery P, Wiggs L. The psychosocial problems of children with narcolepsy and those with excessive daytime sleepiness of uncertain origin. Pediatrics 2006;118:el116-el123.

15. Nevsimalova S, Jara C, Prihodova I, Kemlink D, Sonka K, Skibova J. Clinical features of childhood narcolepsy. Can cataplexy be foretold? Eur J Paediatr Neurol 2011;15:320325.

16. Inocente $\mathrm{CO}$, Lavault $\mathrm{S}$, Lecendreux $\mathrm{M}$, et al. Impact of obesity in children with narcolepsy. CNS Neurosci Ther 2013;19:521-528.
17. Snow A, Gozal E, Malhotra A, et al. Severe hypersomnolence after pituitary/hypothalamic surgery in adolescents: Clinical characteristics and potential mechanisms. Pediatrics 2002;110:e74.

18. Drake C, Nickel C, Burduvali E, Roth T, Jefferson C, Pietro B. The pediatric daytime sleepiness scale (PDSS): Sleep habits and school outcomes in middle-school children. Sleep 2003;26:455-458.

19. Murali H, Kotagal S. Off-label treatment of severe childhood narcolepsy-cataplexy with sodium oxybate. Sleep 2006;29:1025-1029.

20. Kovacs M. The Children's Depression, Inventory (CDI) Psychopharmacol Bull 1985;21:995-998.

21. van Beek Y, Hessen DJ, Hutteman R, Verhulp EE, van Leuven $M$. Age and gender differences in depression across adolescence: Real or 'bias'? J Child Psychol Psychiatry 2012;53:973-985.

22. Bastien $\mathrm{CH}$, Vallieres $\mathrm{A}$, Morin $\mathrm{CM}$. Validation of the Insomnia Severity Index as an outcome measure for insomnia research. Sleep Med 2001;2:297-307.

23. Goyette $\mathrm{CH}$, Conners $\mathrm{CK}$, Ulrich RF. Normative data on revised Conners Parent and Teacher Rating Scales. J Abnorm Child Psychol 1978;6:221-236.

24. Chalder T, Berelowitz G, Pawlikowska T, et al. Development of a fatigue scale. J Psychosom Res 1993;37:147-153.

25. Simeoni MC, Auquier P, Antoniotti S, Sapin C, San Marco JL. Validation of a French health-related quality of 
life instrument for adolescents: The VSP-A. Qual Life Res 2000;9:393-403.

26. Gras D. Santé et qualité de vie des frères et soeurs d'enfants atteints de maladies chroniques. Nantes: Medical Thesis, Nantes Medical University, 2009.

27. Simeoni MC, Sapin C, Antoniotti S, Auquier P. Health-related quality of life reported by French adolescents: A predictive approach of health status? $J$ Adolesc Health 2001;28:288-294.

28. Serra-Sutton V, Ferrer M, Rajmil L, Tebe C, Simeoni MC, Ravens-Sieberer U. Population norms and cut-off-points for suboptimal health related quality of life in two generic measures for adolescents: The Spanish VSP-A and KINDL-R. Health Qual Life Outcomes 2009;7:35.

29. Iber C, Ancoli-Israel S, Chesson AL, Jr., Quan SF. for the Amercian Academy of Sleep Medicine. The AASM manual for the scoring of sleep and associated events: Rules, terminology and technical specifications, 1st edn. Westchester, IL: American Academy of Sleep Medicine, 2007.

30. Challamel MJ, Mazzola ME, Nevsimalova S, Cannard C, Louis J, Revol M. Narcolepsy in children. Sleep 1994;17: S17-S20.

31. Rolland-Cachera MF. Childhood obesity: Current definitions and recommendations for their use. Int $J$ Pediatr Obes 2011;6:325-331.

32. Cole TJ, Bellizzi MC, Flegal KM, Dietz WH. Establishing a standard definition for child overweight and obesity worldwide: International survey. BMJ 2000;320:12401243.

33. Rolland JC. Obesity in adolescence. A childhood story. Arch Pediatr 2004;11:623-624.

34. Kaplowitz PB, Oberfield SE. Reexamination of the age limit for defining when puberty is precocious in girls in the United States: Implications for evaluation and treatment. Drug and Therapeutics and Executive Committees of the Lawson Wilkins Pediatric Endocrine Society. Pediatrics 1999; 104:936-941.

35. Gaudineau A, Ehlinger V, Vayssiere C, Jouret B, Arnaud C, Godeau E. Factors associated with early menarche: Results from the French Health Behaviour in School-aged Children (HBSC) study. BMC Public Health 2010;10:175.

36. Tanner J. Growth at adolescence, 2nd edn. Oxford: Blackwell Publications, 1962.

37. Starfield B, Riley AW, Green BF, et al. The adolescent child health and illness profile. A population-based measure of health. Med Care 1995;33:553-566.

38. Ravens-Sieberer U, Bullinger M. Assessing health-related quality of life in chronically ill children with the German KINDL: First psychometric and content analytical results. Qual Life Res 1998;7:399-407.

39. Jennum P, Ibsen R, Petersen ER, Knudsen S, Kjellberg J. Health, social, and economic consequences of narcolepsy: A controlled national study evaluating the societal effect on patients and their partners. Sleep Med 2012;13:1086-1093.

40. Ohayon MM. Narcolepsy is complicated by high medical and psychiatric comorbidities: A comparison with the general population. Sleep Med 2013;14:488-492.

41. Daniels E, King MA, Smith IE, Shneerson JM. Health-related quality of life in narcolepsy. $J$ Sleep Res 2001;10:75-81.

42. Vignatelli L, D'Alessandro R, Mosconi $\mathrm{P}$, et al. Health-related quality of life in Italian patients with narcolepsy: The SF-36 health survey. Sleep Med 2004;5:467-475.

43. Vignatelli L, Plazzi G, Peschechera F, Delaj L, D'Alessandro R. A 5-year prospective cohort study on health-related quality of life in patients with narcolepsy. Sleep Med 2011;12:19-23.

44. Dodel R, Peter H, Spottke A, et al. Health-related quality of life in patients with narcolepsy. Sleep Med 2007;8:733741.

45. Mosko S, Zetin M, Glen S, et al. Self-reported depressive symptomatology, mood ratings, and treatment outcome in sleep disorders patients. J Clin Psychol 1989;45:51-60.

46. Broughton WA, Broughton RJ. Psychosocial impact of narcolepsy. Sleep 1994;17:S45-S49.

47. Peraita-Adrados R, Garcia-Penas J, Ruiz-Falco L, et al. Clinical, polysomnographic and laboratory characteristics of narcolepsy-cataplexy in a sample of children and adolescents. Sleep Med 2011;12:24-27.

48. Aran A, Einen M, Lin L, Plazzi G, Nishino S, Mignot E. Clinical and therapeutic aspects of childhood narcolepsy-cataplexy: A retrospective study of 51 children. Sleep 2010;33:1457-1464.

49. Nunn JD, Mathews A, Trower P. Selective processing of concern-related information in depression. $\mathrm{Br} J \mathrm{Clin}$ Psychol 1997;36(Pt 4):489-503.

50. Dozois DJ, Dobson KS. Information processing and cognitive organization in unipolar depression: Specificity and comorbidity issues. J Abnorm Psychol 2001;110:236246.

51. Broughton R, Ghanem Q, Hishikawa Y, Sugita Y, Nevsimalova S, Roth B. Life effects of narcolepsy in 180 patients from North America, Asia and Europe compared to matched controls. Can J Neurol Sci 1981;8:299-304.

52. Dodel R, Peter H, Walbert T, et al. The socioeconomic impact of narcolepsy. Sleep 2004;27:1123-1128.

53. Teixeira VG, Faccenda JF, Douglas NJ. Functional status in patients with narcolepsy. Sleep Med 2004;5:477-483.

\section{Supporting Information}

The following supplementary material is available for this article:

Table S1. Demographic and anthropometric characteristics of control subjects and narcoleptic patients whom the parents had filled the HRQL questionnaires.

Table S2. Sleepiness, fatigue, mood, hyperactivity, quality of life, and school problems in control subjects and narcoleptic patients whom parents had filled the HRQL questionnaires.
Table S3. Multivariate model for depression and HRQL in narcoleptic patients.

Table S4. Multivariate model for depression and HRQL in control subjects. 